NASA/TM-2003-212509

\title{
A Time Domain Analysis of Gust-Cascade Interaction Noise
}

M. Nallasamy

QSS Group, Inc., Cleveland, Ohio

R. Hixon

University of Toledo, Toledo, Ohio

S.D. Sawyer

University of Akron, Akron, Ohio

R.W. Dyson

Glenn Research Center, Cleveland, Ohio 
Since its founding, NASA has been dedicated to the advancement of aeronautics and space science. The NASA Scientific and Technical Information (STI) Program Office plays a key part in helping NASA maintain this important role.

The NASA STI Program Office is operated by Langley Research Center, the Lead Center for NASA's scientific and technical information. The NASA STI Program Office provides access to the NASA STI Database, the largest collection of aeronautical and space science STI in the world. The Program Office is also NASA's institutional mechanism for disseminating the results of its research and development activities. These results are published by NASA in the NASA STI Report Series, which includes the following report types:

- $\quad$ TECHNICAL PUBLICATION. Reports of completed research or a major significant phase of research that present the results of NASA programs and include extensive data or theoretical analysis. Includes compilations of significant scientific and technical data and information deemed to be of continuing reference value. NASA's counterpart of peerreviewed formal professional papers but has less stringent limitations on manuscript length and extent of graphic presentations.

- TECHNICAL MEMORANDUM. Scientific and technical findings that are preliminary or of specialized interest, e.g., quick release reports, working papers, and bibliographies that contain minimal annotation. Does not contain extensive analysis.

- CONTRACTOR REPORT. Scientific and technical findings by NASA-sponsored contractors and grantees.
- CONFERENCE PUBLICATION. Collected papers from scientific and technical conferences, symposia, seminars, or other meetings sponsored or cosponsored by NASA.

- SPECIAL PUBLICATION. Scientific, technical, or historical information from NASA programs, projects, and missions, often concerned with subjects having substantial public interest.

- TECHNICAL TRANSLATION. Englishlanguage translations of foreign scientific and technical material pertinent to NASA's mission.

Specialized services that complement the STI Program Office's diverse offerings include creating custom thesauri, building customized databases, organizing and publishing research results ... even providing videos.

For more information about the NASA STI Program Office, see the following:

- Access the NASA STI Program Home Page at http://www.sti.nasa.gov

- E-mail your question via the Internet to help@sti.nasa.gov

- Fax your question to the NASA Access Help Desk at 301-621-0134

- Telephone the NASA Access Help Desk at 301-621-0390

- Write to:

NASA Access Help Desk

NASA Center for AeroSpace Information 7121 Standard Drive

Hanover, MD 21076 
NASA/TM-2003-212509

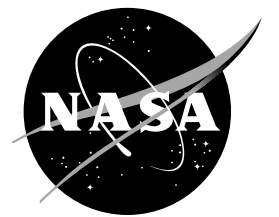

\section{A Time Domain Analysis of Gust-Cascade Interaction Noise}

M. Nallasamy

QSS Group, Inc., Cleveland, Ohio

R. Hixon

University of Toledo, Toledo, Ohio

S.D. Sawyer

University of Akron, Akron, Ohio

R.W. Dyson

Glenn Research Center, Cleveland, Ohio

Prepared for the

Ninth Aeroacoustics Conference and Exhibit cosponsored by the American Institute of Aeronautics and Astronautics and the Confederation of European Aerospace Societies

Hilton Head, South Carolina, May 12-14, 2003

National Aeronautics and

Space Administration

Glenn Research Center 


\section{Acknowledgments}

The authors would like to thank Dr. Envia for designing the 2-D cascade benchmark problem and for his many helpful comments on the solution. The problem is fully described at: http://www.math.fsu.edu/caa4. Thanks are also due to Dr. Miller for the Intel Pentium pc cluster setup, administration, its upgrade and health and to Ms. Koch for generating the grids initially used for this problem.

Available from

NASA Center for Aerospace Information 7121 Standard Drive

Hanover, MD 21076
National Technical Information Service 5285 Port Royal Road Springfield, VA 22100

Available electronically at http:/ /gltrs.grc.nasa.gov 


\title{
A TIME DOMAIN ANALYSIS OF GUST-CASCADE INTERACTION NOISE
}

\author{
M. Nallasamy \\ QSS Group, Inc. \\ National Aeronautics and Space Administration \\ Glenn Research Center \\ Cleveland, Ohio 44135 \\ S.D. Sawyer \\ University of Akron \\ Akron, Ohio 44325
}

\author{
R. Hixon \\ University of Toledo \\ Toledo, Ohio 43606
}

\begin{abstract}
The gust response of a 2-D cascade is studied by solving the full nonlinear Euler equations employing higher order accurate spatial differencing and time stepping techniques. The solutions exhibit the exponential decay of the two circumferential mode orders of the cutoff blade passing frequency (BPF) tone and propagation of one circumferential mode order at $2 \mathrm{BPF}$, as would be expected for the flow configuration considered. Two frequency excitations indicate that the interaction between the frequencies and the self interaction contribute to the amplitude of the propagating mode.
\end{abstract}

\section{INTRODUCTION}

One of the main contributors to fan tone noise is the so-called rotor-stator interaction noise. It is the result of the interaction of the periodic disturbances of the rotor blade (mean) wakes with the stator vanes. One method of computing rotorstator interaction was described in detail in [1], in which a two-dimensional strip description of the unsteady aerodynamic interaction between the rotor wakes and the stator vanes is combined with a 3-D acoustic response of an annular cascade to an incident gust. To improve the computation of unsteady aerodynamics, a time-linearized analysis method is used in [2], where a linearized Euler analysis is shown to produce reasonably well the first two harmonics of the blade passing frequency (BPF). On the other hand, nonlinear time-domain analyses would enable understanding of linearnonlinear regimes, self interactions and interactions of two-frequencies. At NASA Glenn Research Center, an effort is underway to develop a nonlinear time marching algorithm to examine rotor wake - stator interaction noise. In the present paper a non-linear time marching approach is used to compute the gust response of a 2-D cascade.

The gust cascade interaction problem can be analyzed employing either a time-linearized approach or a nonlinear time marching approach. A number of time-linearized analyses have been carried out starting with the Sears problem of an airfoil encountering a gust. Some of these studies are summarized in [3]. In a time-linearized analysis, the gust is assumed to be a small harmonic perturbation of the uniform steady mean flow, yielding a system of equations in the frequency domain. However, in the recent linearized Euler analyses (e. g. [2]) fully nonuniform mean flows are considered. In the time-linearized, frequency domain approach, 
typically the gust response to a single frequency excitation is studied. Nonlinear effects cannot be assessed when the amplitude of excitation is no longer in the linear range.

In a time domain analysis, the full nonlinear Euler equations are solved using a higher order accurate time marching scheme. Of course, the time marching technique requires significantly larger computational time compared to the linearized Euler analysis. But, the advantage of a time domain analysis is that from a single solution for multi-frequency (harmonics) excitation, responses at all harmonics of interest can be extracted. Also, nonlinear interactions [4], both self interaction generating higher frequency responses and interaction between frequencies of excitation resulting in sum and difference tones for multifrequency excitation may be studied. Thus, a true nonlinear time domain analysis has the distinct advantage of being able to mimic the real flow more closely. However, to be able to resolve the nonlinear effects, higher order accurate spatial derivative schemes, time marching schemes, and boundary condition treatments are essential.

The computational time requirements and resolution constraints have so far limited the time domain analysis to single airfoil gust response analyses [5-7] and flat plate cascade [8-9] studies. In the present paper, a cascade representing a typical modern high-speed configuration and a gust typical of the measured wake flow behind a modern high-speed fan rotor are considered. Following the description of the cascade problem, the solution procedure is described briefly. The results for single and two-frequency excitations are presented and discussed. Nonlinear effects observed in single and two-frequency excitations are also examined.

\section{THE PROBLEM}

The 2-D cascade geometry shown in Figure 1 is the unrolled section at a radial location of a modern high speed turbofan stator vane geometry. The cascade has a gap-to-chord ratio of $\mathrm{d} / \mathrm{c}=2 / 3$ with the inflow and outflow planes located at $\mathrm{x}=3 / 2 \mathrm{c}$, where $\mathrm{c}$ is the vane chord, and $\mathrm{d}$ is the vane gap. The mean flow conditions at the inflow and outflow planes are given as:

Inflow: $\mathrm{P}_{\mathrm{i}}=1, \mathrm{~T}_{\mathrm{i}}=1$, and $\alpha_{\mathrm{i}}=36^{\circ}$

Outflow: $\mathrm{p}_{\mathrm{o}} / \mathrm{P}_{\mathrm{i}}=0.92$

where $P_{i}$ and $T_{i}$ are the normalized mean stagnation pressure and stagnation temperature respectively. $\alpha_{i}$ is the mean flow angle and $p_{o}$ is the mean static pressure at the outflow plane. The inflow periodic wake disturbance is described at the inflow plane as follows:

$$
\begin{aligned}
& \vec{u}_{g}^{\prime}(y, t)=\left\{a_{1} \cos \left(k_{y} y-\omega t\right)+\right. \\
& \left.\left.a_{2} \cos \left(2\left(k_{y} y-\omega t\right)+\varphi_{2}\right)\right)\right\} \hat{e}_{\beta} \\
& \rho_{g}^{\prime}(y, t)=0, \quad p_{g}^{\prime}(y, t)=0 \\
& \hat{e}_{\beta}=\cos (\beta) \hat{e}_{x}-\sin (\beta) \hat{e}_{y}, \quad \beta=50^{\circ} \\
& \begin{array}{l}
\omega=3 \pi / 4, \quad \mathrm{k}_{\mathrm{y}}=11 \pi / 9, \quad \mathrm{a}_{1}=0.007, \\
\mathrm{a}_{2}=0.003, \quad \varphi_{2}=-7 \pi / 5 .
\end{array}
\end{aligned}
$$

where $\omega$ is the fundamental reduced frequency, $\mathrm{k}_{\mathrm{y}}$ is the transverse wavenumber, and $\mathrm{a}_{\mathrm{i}}$ 's are the gust harmonic amplitudes. The frequency is normalized by the chord divided by the ambient speed of sound, wavenumber is normalized by the vane chord, and gust amplitudes are normalized by the ambient speed of sound. The harmonic amplitudes of excitation $\mathrm{a}_{1}$ (at BPF), and $\mathrm{a}_{2}$ (at 2BPF) have been varied to study the nonlinearities associated with the high amplitudes and two-frequency excitations.

\section{GOVERNING EQUATIONS}

The full nonlinear Euler equations governing the 2-D cascade flow are solved in the present investigation. In Cartesian coordinates these equations are written as:

$$
\frac{\partial Q}{\partial t}+\frac{\partial E}{\partial x}+\frac{\partial F}{\partial y}=0
$$

where 


$$
\begin{gathered}
Q=\left[\begin{array}{l}
\rho \\
\rho u \\
\rho v \\
E
\end{array}\right] \\
E=\left[\begin{array}{l}
\rho u \\
\rho u^{2}+p \\
\rho u v \\
u(E+p)
\end{array}\right] \\
F=\left[\begin{array}{l}
\rho v \\
\rho u v \\
\rho v^{2}+p \\
v(E+p)
\end{array}\right]
\end{gathered}
$$

and

$$
p=(\gamma-1)\left\{E-\frac{1}{2} \rho\left(u^{2}+v^{2}\right)\right\}
$$

These equations are cast in generalized curvilinear coordinates employing the chain rule formulation as:

$$
\frac{\partial Q}{\partial \tau}+\frac{\partial \xi \partial E}{\partial x \partial \xi}+\frac{\partial \eta \partial E}{\partial x \partial \eta}+\frac{\partial \xi \partial F}{\partial y \partial \xi}+\frac{\partial \eta \partial F}{\partial y \partial \eta}=0
$$

\section{SOLUTION PROCEDURE}

The full nonlinear time dependent Euler equations governing the 2-D cascade flow are solved employing a new parallel computational aeroacoustic (CAA) code developed by Hixon et al. described in part in [10]. Details of the computational scheme may be found in [11-12]. Since the flow has a wide range of length and time scales, a higher order numerical scheme is needed to reduce dissipation and dispersion errors. The code solves the flow equations written in chainrule curvilinear form, using a prefactored sixthorder compact scheme for spatial differencing, with 11-point explicit stencils at the block boundaries. An explicit $10^{\text {th }}$ order constant coefficient artificial dissipation is used for damping. The time marching uses a $2 \mathrm{~N}$ Storage fourth-order nonlinear extension of Hu's 5-6 Low Dissipation and Dispersion Runge-Kutta (LDDRK) scheme $[13,14]$. The inflow and outflow boundary conditions are implemented using Giles nonreflecting boundary conditions [15]. On the airfoils, the time derivative of the velocity normal to the wall is set to zero.

In the present computations, grid singularities have been removed. However, it was shown in [16] that grid singularities have negligible effect on the converged solution. The technique of implementing mean flow boundary conditions are discussed in [17] and the effects of higher order wall boundary conditions on the solution are explored in [18].

\section{NUMERICAL SOLUTION}

The fan stage considered in this study has a 22 bladed rotor and a 54 vane stator. The propagating acoustic modes are determined from the TylerSofrin [19] criterion, $m=n N_{b}-k N_{v}$, where $m$ is the circumferential mode order, $\mathrm{n}$ the harmonic number, $\mathrm{N}_{\mathrm{b}}$ number of rotor blades, $\mathrm{N}_{\mathrm{v}}$ number of stator vanes and $\mathrm{k}$ a positive integer. For the fan stage considered here, the blade passing frequency (BPF) tone is cutoff. That is, the BPF interaction mode $m=-32$, and the rotor locked mode $m=22$ are expected to decay exponentially. The propagating mode is $m=-10$ at $2 \mathrm{BPF}$. Because of periodicity, it is enough to simulate one half of the fan. In the rolled out $2-\mathrm{D}$ cascade, only 27 stator passages need to be considered and accordingly the propagating mode is also stated as $\mathrm{m}=-5$. The decaying modes at BPF are $m=-16$ and $m=11$ for this cascade.

The grid used in the computations has nine grid blocks per passage (Figure 2), with 12704 grid points, and 27 passages are solved as mentioned above. An initial grid tested had 6 grid blocks (with 7004 points per passage) which provided reasonable flow resolution and acoustic response 
amplitudes. However, the grid shown in Figure 2 was chosen to significantly increase the flow resolution in the leading edge, trailing edge, and wake regions. The grid density varies depending on the region of the flow. In this grid, the minimum number of grid points in the axial direction is 124 and in the lateral direction is 46 . The minimum number of points per wavelength at 2BPF is 41 and thus the grid density is sufficient to produce the resolutions required for the excitation frequencies considered. For each set of gust amplitudes, the solution is run till periodicity in pressure is achieved on the inflow, outflow boundaries and on the airfoil surface. In terms of the period of the BPF harmonic, it was found that the solution is to be run about 200 periods. Once the periodic solution is established, it is postprocessed to extract the modal information. A joint spatial - temporal Fourier transform of the acoustic pressure $\mathrm{p}(\mathrm{x}, \mathrm{y}, \mathrm{t})$, provides the amplitude of the acoustic waves as a function of rotor harmonic $\mathrm{n}$, spatial mode order $\mathrm{m}$, and axial location x [20]. To perform a Fast Fourier Transform (FFT) the number of samples employed is usually a power of two. Since FFT is done over the entire computational domain, the number of samples cannot be too large. But, it was found that a minimum of 32 samples (points in the time series) is needed to avoid aliasing problems.

\section{RESULTS AND DISCUSSION}

The time domain analysis is employed to study the acoustic response to single frequency and two frequency excitations. Single and two-frequency excitation responses are compared and linear and nonlinear characteristics are examined.

\section{BPF excitation:}

The unsteady flow features that are observed in the present gust-cascade interaction problem for a 2 BPF, single frequency excitation is first presented in Figure 3. As described above the solution is carried out for the 27 passages. However, to illustrate the unsteady flow characteristics only three full passages are shown. The imaginary part of unsteady u-velocity contours (Figure 3a) indicate the nature of the gust convected through the passage. The wake behind the trailing edge is thicker than that would be observed in a linearized solution. This is also illustrated in the instantaneous u-velocity (Figure $3 b$ ) and vorticity (Figure 3c) contours. The oscillations in the vorticity contours from the airfoil surface and the wake are typical of high accuracy fine grid solutions. Computed results indicate that the thickness of the vortex sheet behind the trailing edge and the magnitude of the vorticty in the wake are functions of the amplitude of excitation.

Figure $3 \mathrm{~d}$ shows the contours of the imaginary part of unsteady pressure. The circumferential mode order $(\mathrm{m})$ pattern is observed. The mode order $\mathrm{m}=-5$ is propagating both in the inflow and outflow regions. The clean and nearly straight contours near the inflow $(x=-1.5)$ and near the outflow $(x=1.5)$ planes suggest that the reflection from the boundaries is minimal. The high accuracy spatial differencing scheme and the time stepping scheme contribute to the quality of the solution.

The circumferential mode pattern in the entire computational domain is shown in Figure 4a. The propagating circumferential mode order, $m=-5$ is clearly seen both in the inflow and outflow regions. As indicated above, at the inflow and outflow planes the reflection appears to be small and seems not to affect the solution. The propagating mode amplitude as a function of axial distance $\mathrm{x}$ is shown for the inflow region in Figure $4 \mathrm{~b}$ and for the outflow region in Figure 4c.

The convergence of the pressure waveforms are examined for the establishment of the periodic solution. The typical pressure waveforms at the airfoil pressure and suction surfaces, inflow plane and outflow plane are shown in Figure 5. The figures show the waveforms at two successive periods, 203T and 204T. The convergence is confirmed by 'no change' in the propagating mode amplitudes in the inflow and outflow regions. The waveforms are extracted from the 64 flow files used in the fast Fourier transform (see section 5). A nearly sinusoidal waveform is obtained at all 4 points for this single frequency, $2 \mathrm{BPF}$ excitation. 


\section{BPF excitation:}

As stated above, for the fan stage (11 rotor blades and 27 stator vanes) considered in the current study, the blade passing frequency tone is cutoff. However, there exist two mode orders, the rotorstator interaction mode $m=-16$ and the rotor locked mode $\mathrm{m}=11$, which decay exponentially with distance from leading and trailing edges. Since two modes exist, the circumferential mode pattern is not as clean and straight as in the case of 2BPF excitation. Also note that the mode order $\mathrm{m}=-16$ dominates in the inflow region while mode order $m=11$ dominates the outflow region. This results in the appearance of the corresponding mode orders in Figure 6a. The decay of these two modes in the inflow region (Figure 6b) and outflow region (Figure 6c) are shown. These cutoff modes decay exponentially as would be expected.

The converged waveforms for the BPF excitation are shown in Figure 7. The airfoil surface pressure waveforms are nearly sinusoidal as for the $2 \mathrm{BPF}$ excitation. However, the inflow plane and outflow plane waveforms show substantial departure from a sinusoidal waveform. This is primarily due to the fact that two circumferential mode orders, $m=11$ and $m=-16$, exist for this excitation.

Effect of Amplitude of Excitation: Single Frequency

The effect of amplitude of excitation on the propagating mode amplitude at $2 \mathrm{BPF}$ is shown in Figures $8 \mathrm{a}$ and $8 \mathrm{~b}$, for the inflow and outflow regions respectively. When the excitation amplitude is 10 times the original amplitude $\left(\mathrm{a}_{2}=0.003\right)$, the $2 \mathrm{BPF}$ response also increases 10 times as shown in Figures $8 \mathrm{a}$ and $8 \mathrm{~b}$. The dashed line in the figures represents the response for the excitation amplitude for $\mathrm{a}_{2}=0.003$ multiplied by a factor of 10. The linearity of the response for the single frequency excitation is clearly exhibited.

For the BPF excitation, the variation of response with the amplitude of excitation for the interaction mode $m=-16$ is shown in figures $8 c$ and $8 d$. In the inflow region, the linearity is maintained for the range of amplitudes from 0.007 to 0.03 . But in the outflow region, the BPF response exhibits a slightly nonlinear behavior which is indicated by the deviation of the dashed line from the solid line for an excitation amplitude of 0.03 .

\section{$\underline{\text { Two-Frequency Excitation }}$}

Next, the acoustic responses for excitation at two frequencies, $\mathrm{BPF}+2 \mathrm{BPF}$, are considered. The excitation amplitudes are $\mathrm{a}_{1}=0.03$ and $\mathrm{a}_{2}=0.003$. The circumferential mode order patterns are shown in Figures $9 \mathrm{a}$ and $9 \mathrm{~b}$ for $\mathrm{BPF}$ and $2 \mathrm{BPF}$, respectively. Figure 9a for $\mathrm{BPF}$, is similar to Figure $6 \mathrm{a}$, the mode pattern observed for $\mathrm{BPF}$ alone excitation. However, the mode order pattern for $2 \mathrm{BPF}$ (Figure 9b) is distinctly different from that observed in Figure $4 \mathrm{a}$ for $2 \mathrm{BPF}$ alone excitation, in particular in the outflow region. This is due to the interaction between frequencies and self interaction as discussed below.

The converged waveforms for the two frequency excitation are shown in Figure 10. Figures 10a and $10 \mathrm{~b}$ show the waveforms on the airfoil surface and $10 \mathrm{c}$ and $10 \mathrm{~d}$ at the inflow and outflow planes, respectively. Note that the waveforms are at the same physical locations as in the single frequency excitations. For two-frequency excitations, the waveforms show substantial departures from the sinusoidal form, but appear similar to that of BPF excitation, indicating the dominance of $\mathrm{BFF}$ excitation amplitude.

As noted before, the BPF tone is cutoff for this fan stage configuration. The decaying BPF tone at circumferential mode orders $m=-16$ and $m=11$ have the same amplitude response for single and two-frequency excitations in both the inflow and outflow regions (Figures 11a-11d). However, the $2 \mathrm{BPF}$ response is significantly different from that for single $2 \mathrm{BPF}$ frequency excitation in the inflow (Figure 11e) and outflow (Figure 11f). This marked difference appears to stem from self interaction and interaction between the frequencies.

\section{Effect of Amplitude of Excitation: Two-frequency}

The gust with the amplitude of BPF, $\mathrm{a}_{1}=0.03$ and 2BPF, $\mathrm{a}_{2}=0.003$ is designated as Gust (see Figure 12). The two amplitudes were decreased to $1 / 2 \quad\left(a_{1}=0.015, \quad a_{2}=0.0015\right), \quad 1 / 4 \quad\left(a_{1}=0.0075\right.$, $\left.\mathrm{a}_{2}=0.00075\right)$, and $1 / 8\left(\mathrm{a}_{1}=0.00375, \mathrm{a}_{2}=0.000375\right)$, 
successively. The responses at these excitations are shown in Figure 12. The dashed lines in the figure represent the values of the response at the lowest (1/8) amplitude multiplied by 2, 4, or 8 times. For Gust amplitude 1/4 almost a linear response is observed. For Gust amplitudes $1 / 2$ and 1 , the responses deviate substantially from the linear multiple of the lowest response amplitude. This again seems to stem from the self interaction, as the BPF amplitude is increased. This is explored further below.

\section{Self interaction}

A single frequency excitation, depending on the amplitude of excitation, can produce higher harmonic responses in addition to the response at the frequency of excitation [4]. In the current study for example, high amplitude BPF excitation can produce response at $2 \mathrm{BPF}$. This is examined in Figure 13, which shows the 2BPF response for BPF excitation amplitudes $0.015,0.0225$, and 0.03 . Also shown for comparison is the $2 \mathrm{BPF}$ response for a $2 \mathrm{BPF}$ amplitude of excitation, $\mathrm{a}_{2}=0.003$. At the inflow, the $2 \mathrm{BPF}$ response increases with increase in amplitude of excitation at BPF. For $\mathrm{a}_{1}=0.015$ there is substantial $2 \mathrm{BPF}$ response while for $a_{1}=0.03$ the $2 \mathrm{BPF}$ response is higher than that for a $2 \mathrm{BPF}$ excitation with $\mathrm{a}_{2}=0.003$ ! At the outflow, the 2BPF response increases with increase in BPF excitation amplitude, but the response amplitudes are smaller compared to that of $2 \mathrm{BPF}$ alone excitation.

\section{$\underline{\text { Two-Frequency Interaction }}$}

When the excitation is at two frequencies, interaction between the frequencies of excitation can occur depending on the relative magnitudes of excitation [4]. The 2BPF response, for two frequency excitations are shown in Figure 14 for three cases: $a_{1}$ alone, $a_{2}$ alone, and $a_{1}+a_{2}$. Figures $14 \mathrm{a}$ and $14 \mathrm{~b}$ show the $2 \mathrm{BPF}$ responses when the amplitudes of excitations are small and equal to 0.003 , while Figures $14 \mathrm{e}$ and $14 \mathrm{f}$ show the response for an amplitude of 0.03. In either case, a nearly linear behavior is observed both at the inflow and outflow regions. Figures $14 \mathrm{c}$ and $14 \mathrm{~d}$ show the responses, when $\mathrm{a}_{1}=0.03$ and $\mathrm{a}_{2}=0.003$. In this case, the interactions modify the response amplitudes substantially. Further analyses are needed to quantify the interaction effects.

\section{CONCLUDING REMARKS}

The acoustic response of a 2-D cascade was examined by solving the full nonlinear Euler equations employing higher order accurate spatial differencing and time stepping methods. Both single frequency (BPF or 2BPF only) and two frequency $(\mathrm{BPF}+2 \mathrm{BPF})$ excitations were considered to facilitate understanding of the results and to compare with each other. Single frequency excitations show a linear response with the amplitude of excitation for a wide range of excitation amplitudes. For two frequency excitations, significant nonlinear effects are observed when the BPF amplitude is high. Self interaction seems to contribute to this behavior. The results of the two frequency excitations also show that a linear behavior exists as long as the amplitudes of excitations are equal. When the BPF excitation amplitude is higher, interaction of the two frequencies and self interaction modify the amplitudes of the propagating $2 \mathrm{BPF}$ mode significantly, both in the inflow and outflow regions. To the authors' knowledge this is the first time that self interaction and twofrequency interactions have been computed, in a time-domain analysis, for a realistic gustcascade interaction configuration. Further analysis is needed to ascertain the validity of the observations and accuracy of the magnitude of the computed interactions. 


\section{REFERENCES}

1. Envia, E and Nallasamy, M, "Design selection and analysis of a swept and leaned stator concept," Journal of Sound and Vibration, Vol. 228, pp. 793836, 1999.

2. Verdon, J.M., "Linearized unsteady aerodynamic analysis of the acoustic response to wake/blade row interaction," NASA CR-210713, 2001.

3. Groneweg, J.F, Sofrin, T.G, Rice, E.J., and Gliebe, P.R., "Turbomachinery Noise," in Aeroacoustics of Flight Vehicles: Theory and Practice Volume 1: Noise sources, NASA RP1258, WRDC Technical Report 90-3052, 1991.

4. Morse, P.M. and Ingard, K.U., "Theoretical Acoustics," pp. 870-873, McGraw-Hill, New York, 1968.

5. Hixon, R., Shih, S.-H., Mankabadi, R.R., Scott, J.R., "Time domain solution of airfoil scheme," AIAA Paper 98-3241, 1998.

6. Lockard, D.P. and Morris, P.J., "Radiated noise from airfoils in realistic mean flow," AIAA Journal, Vol. 36, pp.907-914, 1998

7. Lockard, D.P. and Morris, P.J.," A parallel implementation of a computational aeroacoustic algorithm for airfoil noise," AIAA Paper 96-1754, 1996.

8. Hixon, R., Shih, S. -H., Mankabadi, R.R., "Evaluation of Boundary conditions for the Gust-Cascade problem," Journal of Propulsion and Power, Vol. 16, pp. 72-78, 2000.

9. Lockard, D.P. and Morris, P.J., "A parallel simulation of gust-cascade interaction noise," $2^{\text {nd }}$ Computational Aeroacoustics Workshop on benchmark problems, NASA CP-3352, pp. 279288, 1997.

10. Hixon, R, Nallasamy, M. and Sawyer, S.D, "Parallelization strategy for an explicit computational aeroacoustic code," AIAA Paper 2002-2583, 2002.
11. Hixon, R, "Nonlinear comparison of high-order and optimized finite-difference schemes, Journal of Computational Fluid Dynamics, Vol. 13, pp. 257277, 2000.

12. Hixon, R, Shih, S.-H., Mankabadi, R.R., "Evaluation of boundary conditions for the gustcascade problem," Journal of Propulsion and Power, Vol. 16, pp. 72-78, 2000.

13. Hu, F.Q., Hussaini, M.Y. and Manthey, J., "Low-Dissipation and dispersion Runge-Kutta schemes for computational acoustics," Journal of Computational physics, Vol. 124, pp. 121-133, 1996

14. Stanescu, D. and Habashi, W.G., "2N-Storage low dissipation and dispersion Runge-Kutta schemes for computational acoustics," Journal of Computational Physics, Vol. 143, pp. 674-681, 1998.

15. Giles, M., "Nonreflecting boundary gust problem using a higher order compact conditions for Euler equation calculations," AIAA Journal, Vol. 28, pp. 2050-2058, 1990.

16. Hixon, R, Nallasamy, M. and Sawyer, S.D. "Effect of grid singularities on the solution accuracy of a CAA code," AIAA Paper 20030879, 2003.

17. Hixon, R, Nallasamy, M. and Sawyer, S.D, Dyson, R.W., "Mean flow boundary conditions for Computational Aeroacoustics," AIAA Paper 2003-3299, 2003.

18. Dyson, R.W. and Hixon, R. "Towards arbitrary accuracy inviscid surface boundary conditions," AIAA Paper 2002-2483, 2002.

19. . Tyler, L.M. and Sofrin, T.G., "Axial flow Compressor noise studies," Transactions of SAE 70, pp. 309-332, 1962.

20. Sawyer, S.D., Nallasamy. M, Hixon, R., and Dyson, R.W., "Explicit computational aeroacoustic prediction of discrete frequency noise generation by rotor-stator interaction, AIAA Paper 20033268, 2003. 


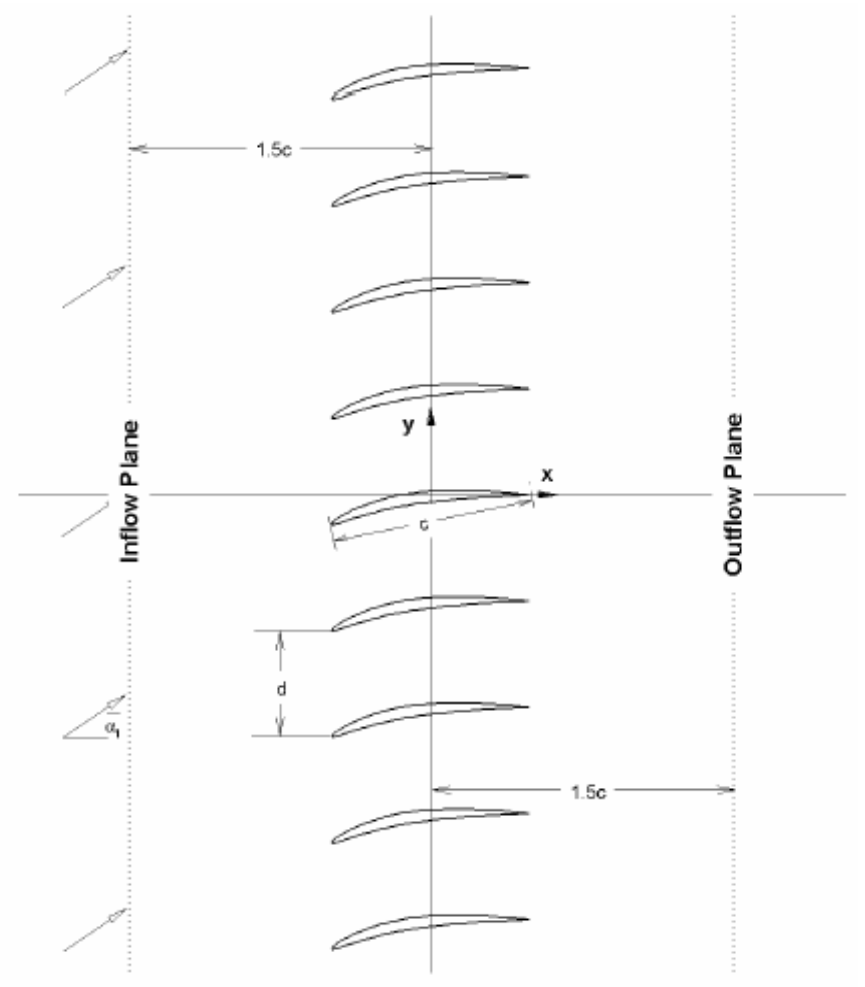

Figure 1.-Cascade geometry definition.

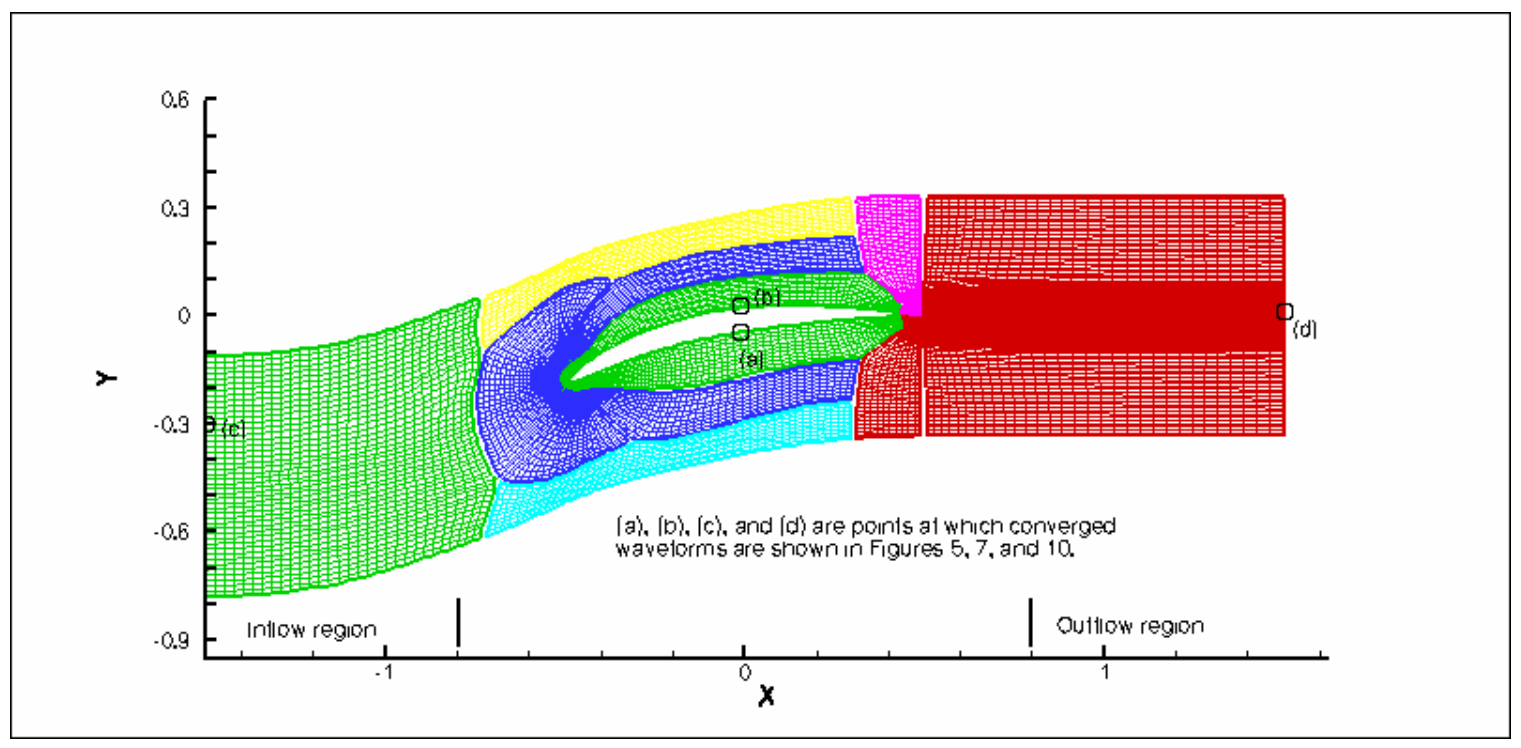

Figure 2.-Typical cascade grid, 9 grid blocks (12,704 points) per passage, used in the simulation. 

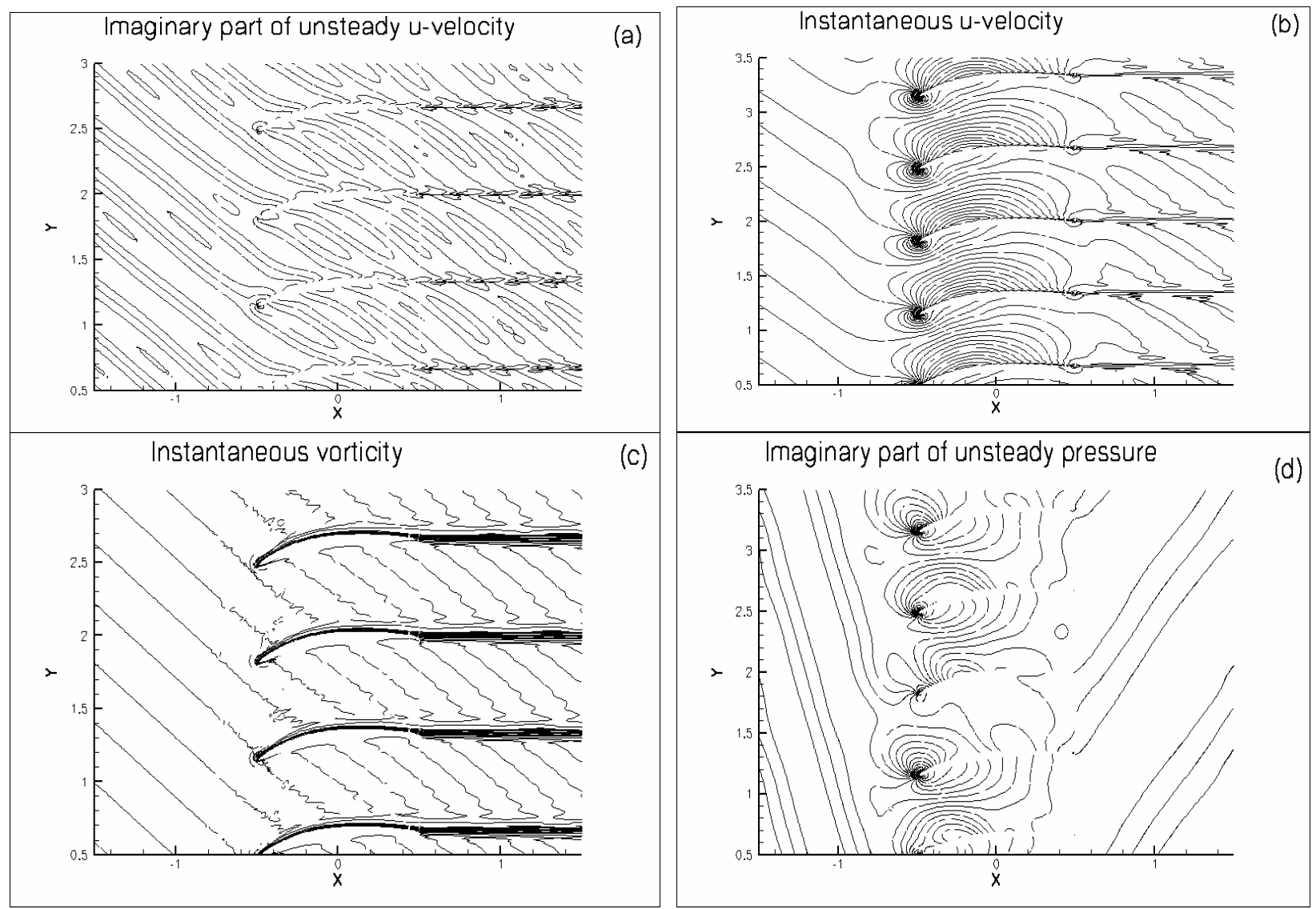

Figure 3.-Cascade unsteady flow features: 2 BPF excitation, $\mathrm{a}_{2}=0.003 ; 27$-passage solution.
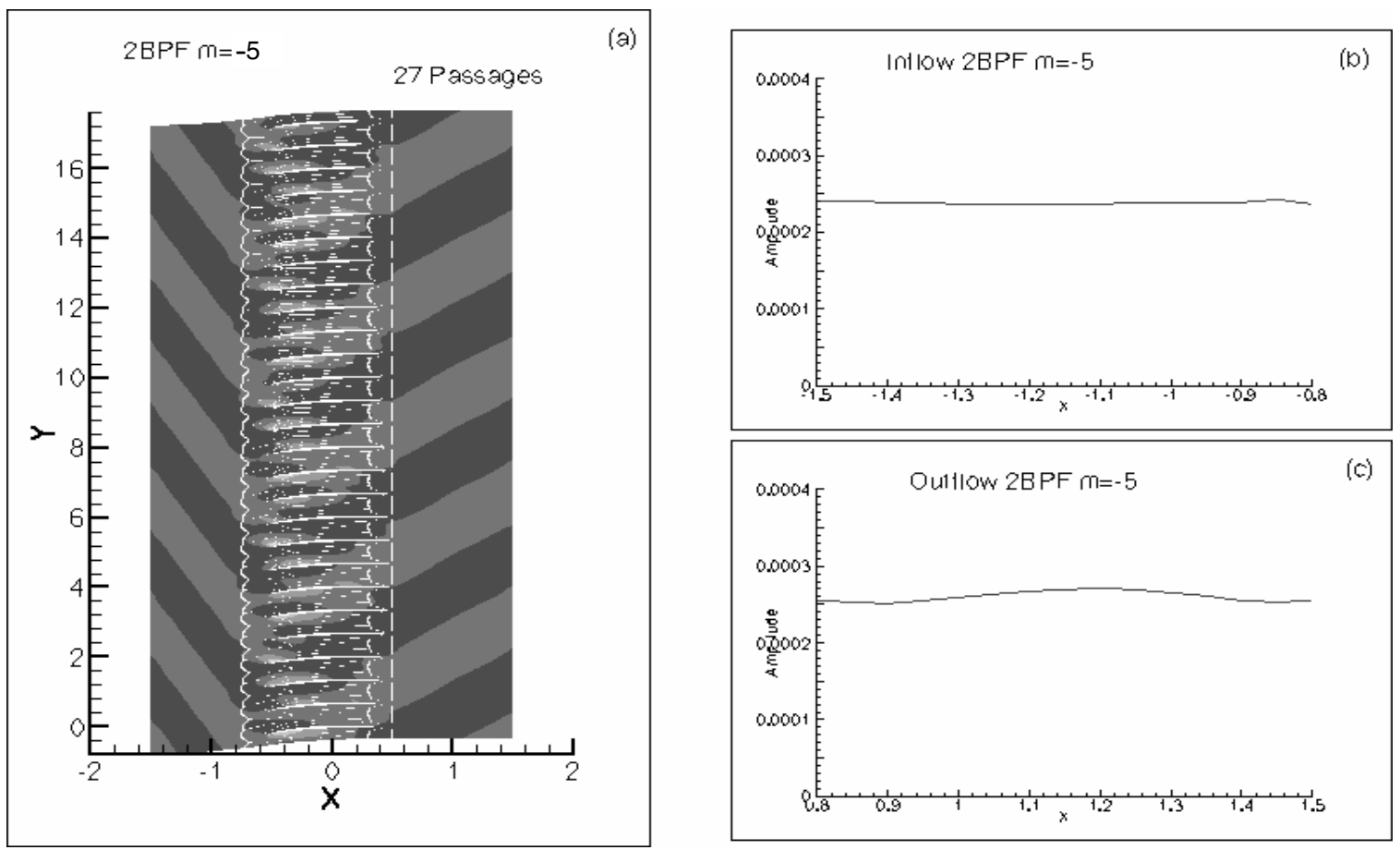

Figure 4. - Cascade (27 passages). 2BPF gust imposed, $\mathrm{a}_{2}=0.003$. Propagating mode order at inflow and outflow: $\mathrm{m}=-5$. 

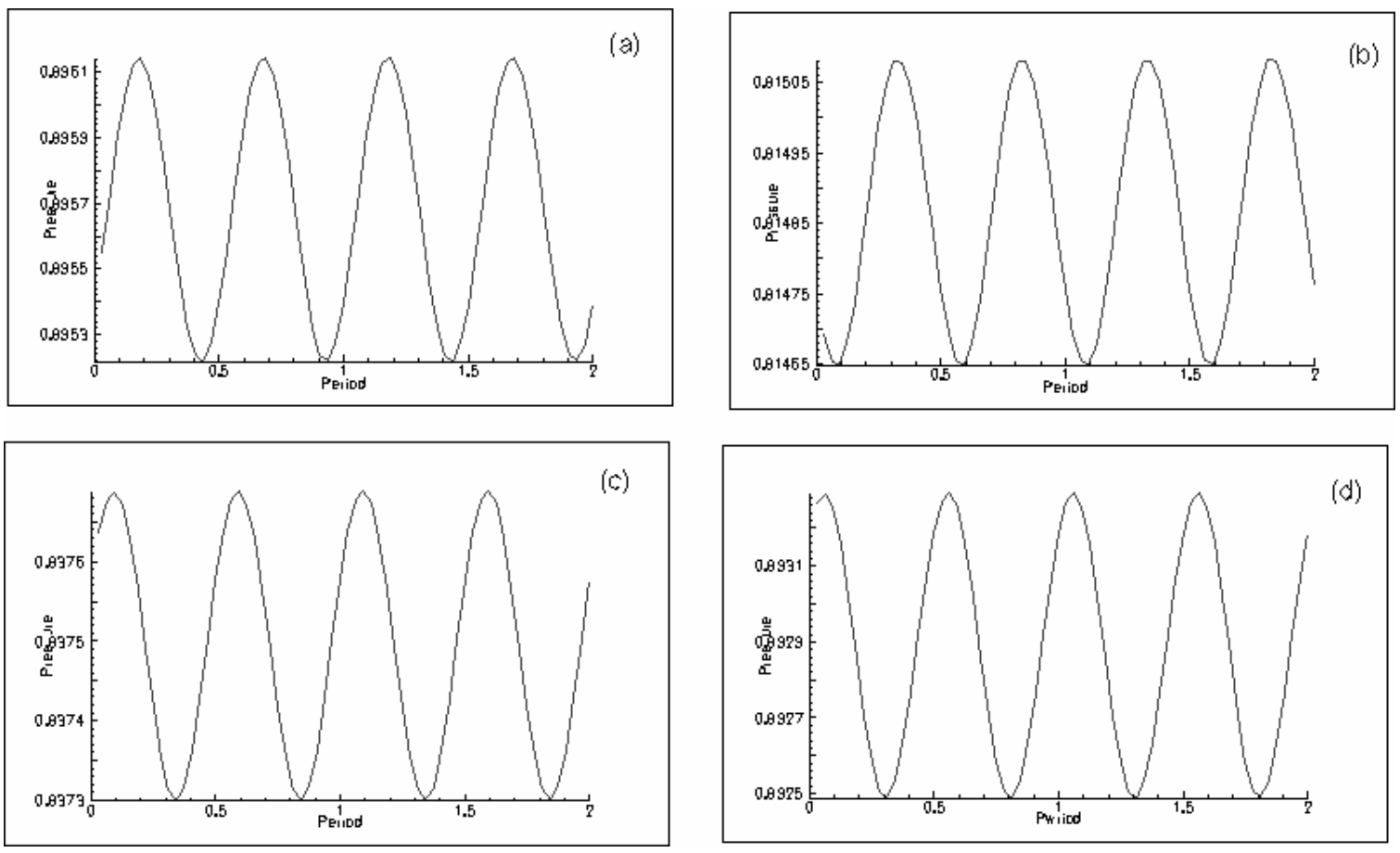

Figure 5.-Converged waveforms for $2 \mathrm{BPF}$ excitation, $\mathrm{a}_{2}=0.003$ : (a) pressure surface (mid chord). (b) suction surface (mid chord). (c) inflow plane $(-1.5,-0.3)$. (d) outflow plane $(1.5,0.0)$.
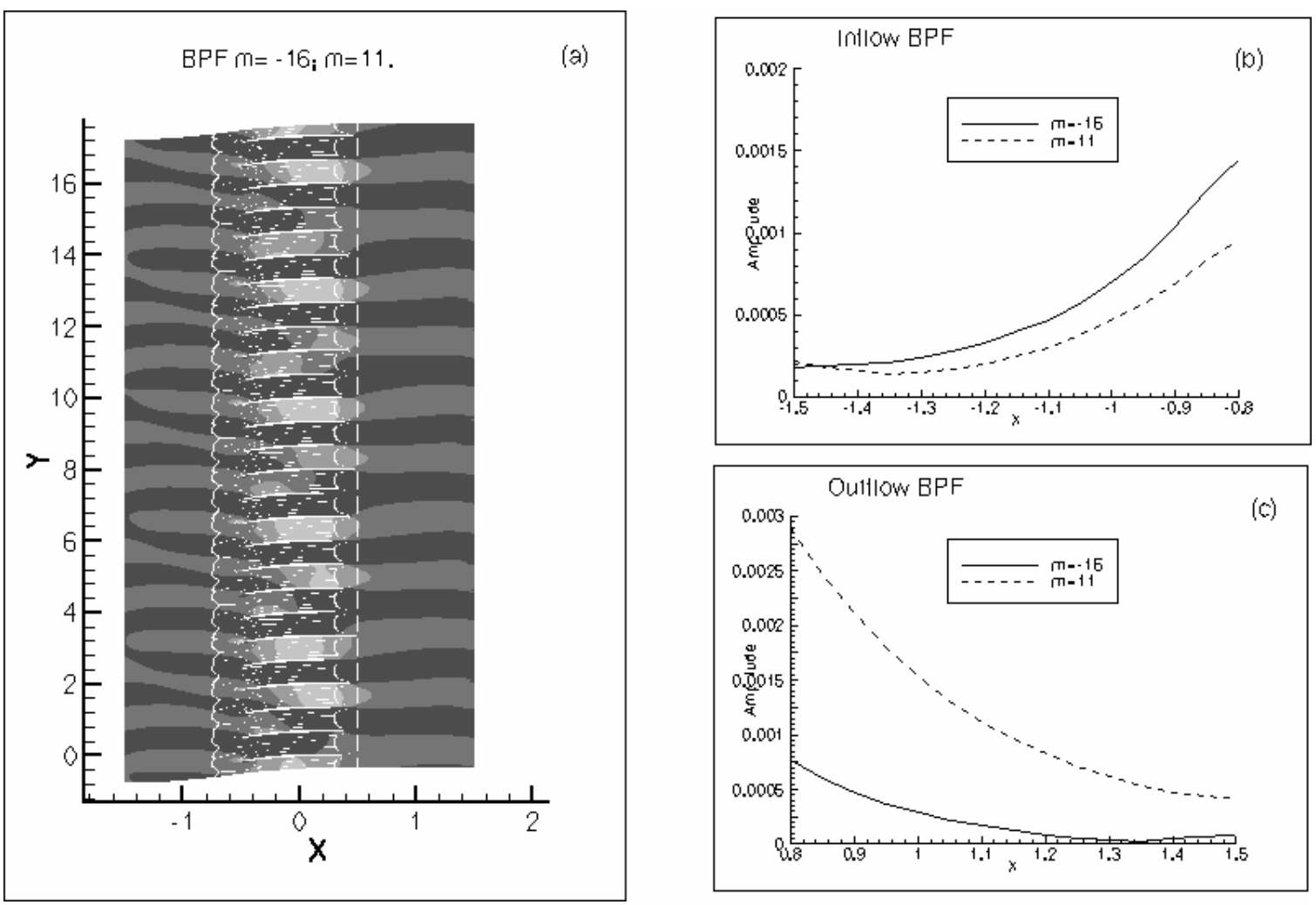

Figure 6.-Circumferential mode pattern for BPF excitation, $\mathrm{a}_{1}=0.03$ and decay of mode amplitudes (cutoff modes). 

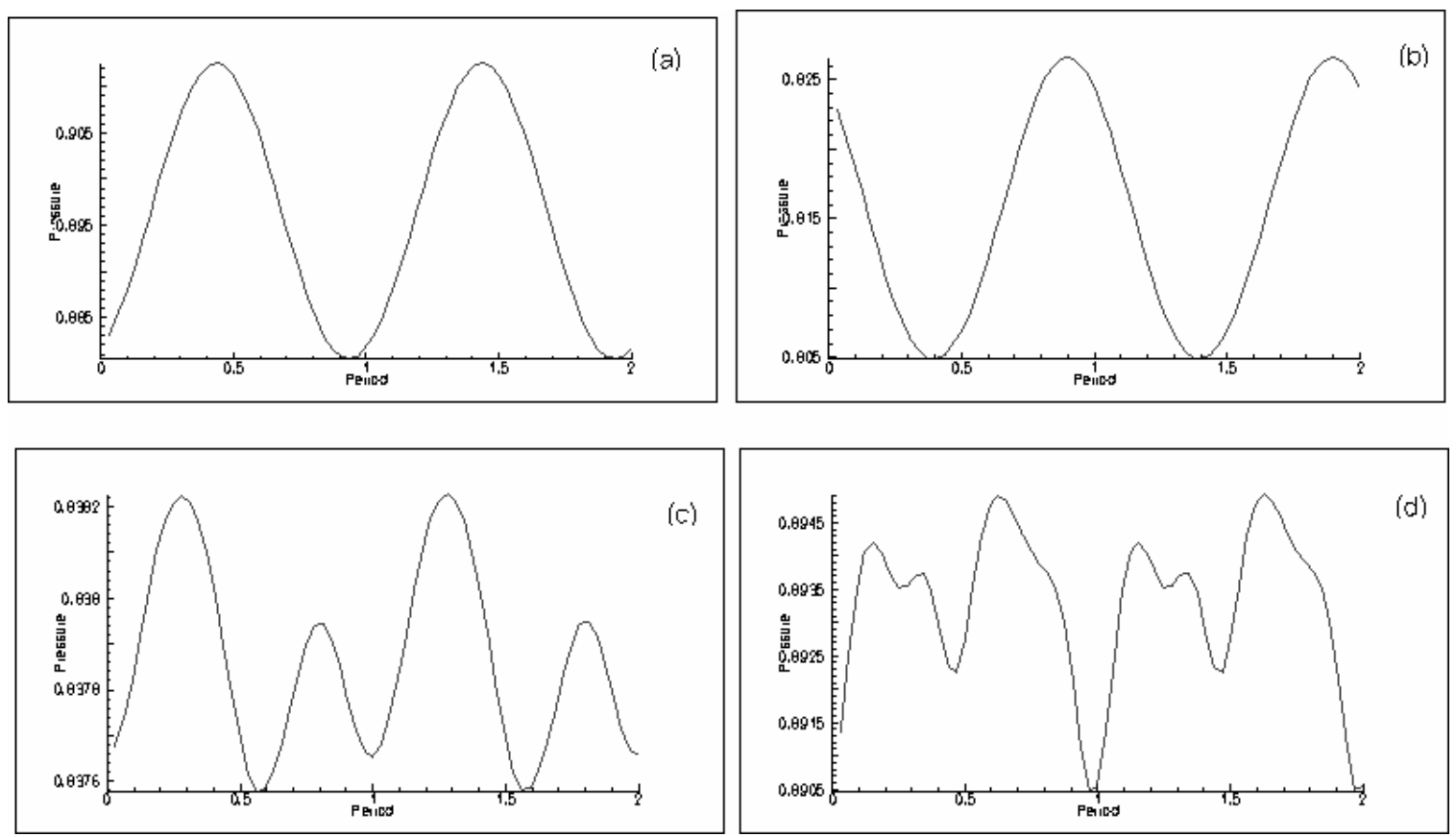

Figure 7.-Converged waveforms for BPF excitation, $\mathrm{a}_{1}=0.03$ : (a) pressure surface (mid chord).

(b) suction surface (mid chord). (c) inflow plane $(-1.5,-0.3)$. (d) outflow plane $(1.5,0.0)$.
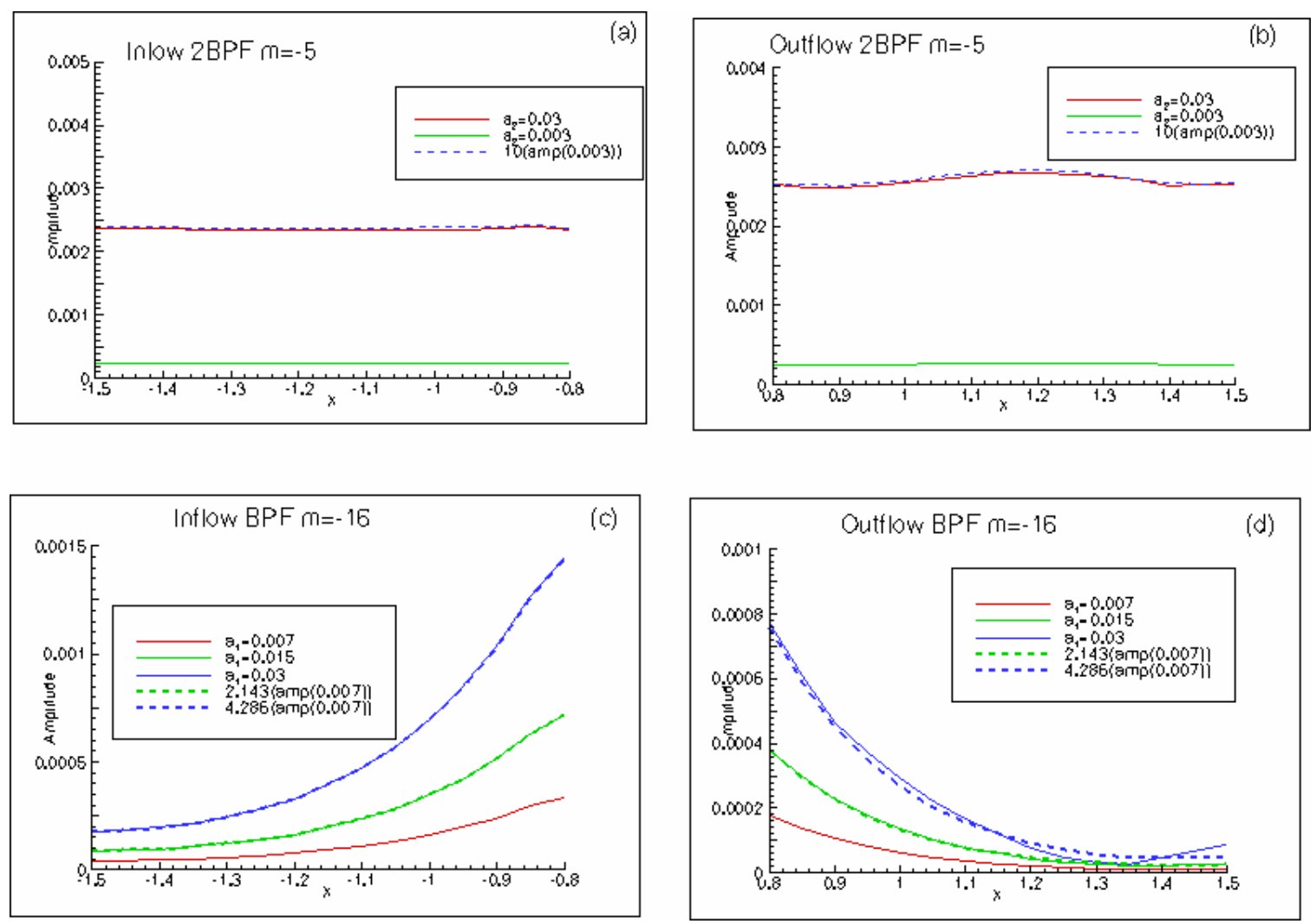

Figure 8.-Single frequency excitations: Effect of amplitude of excitation on propagating 2BPF mode and decaying modes of BPF. 

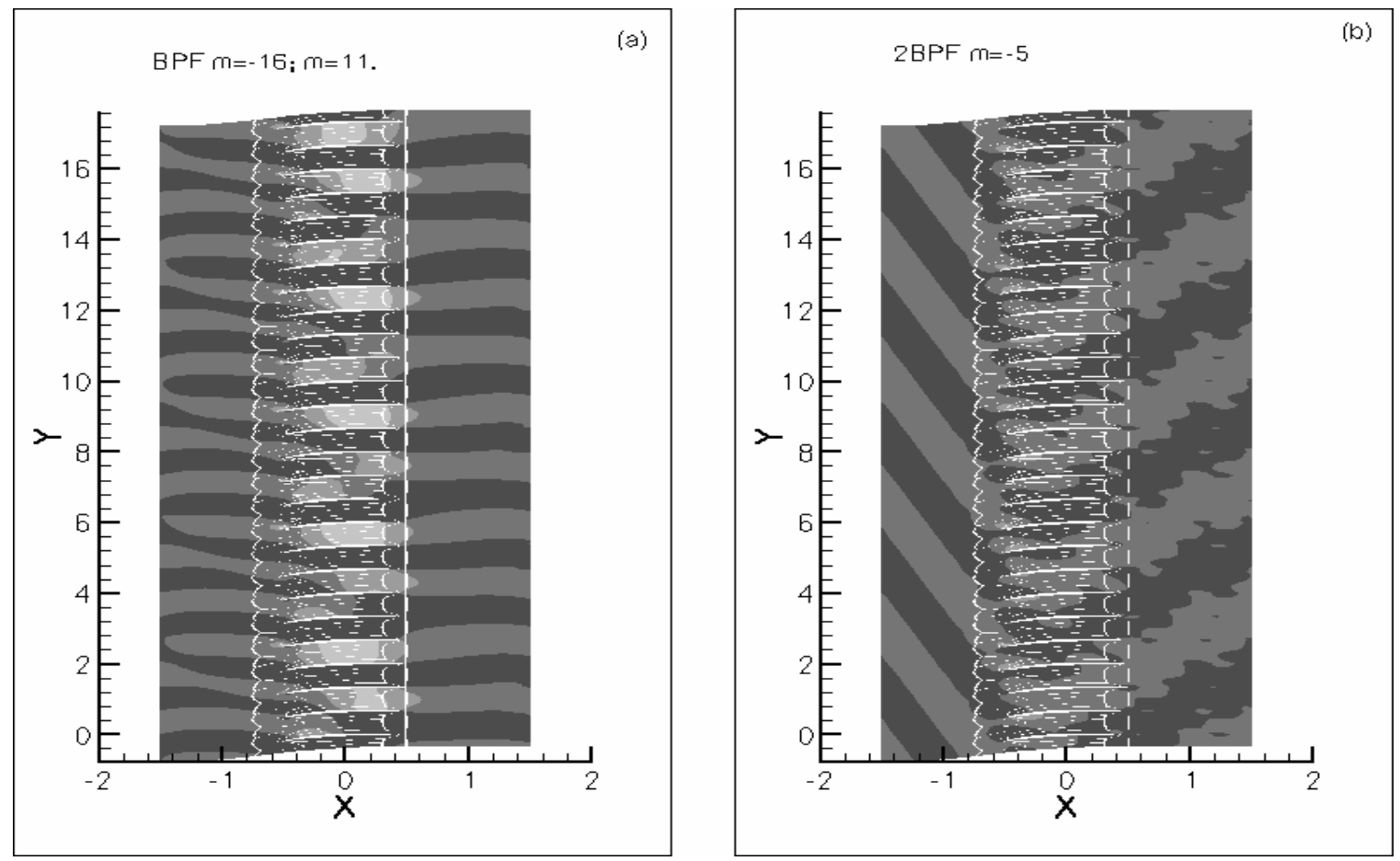

Figure 9.-Circumferential mode order patterns for two frequency excitation: BPF+2BPF; $\mathrm{a}_{1}=0.03, \mathrm{a}_{2}=0.003$.
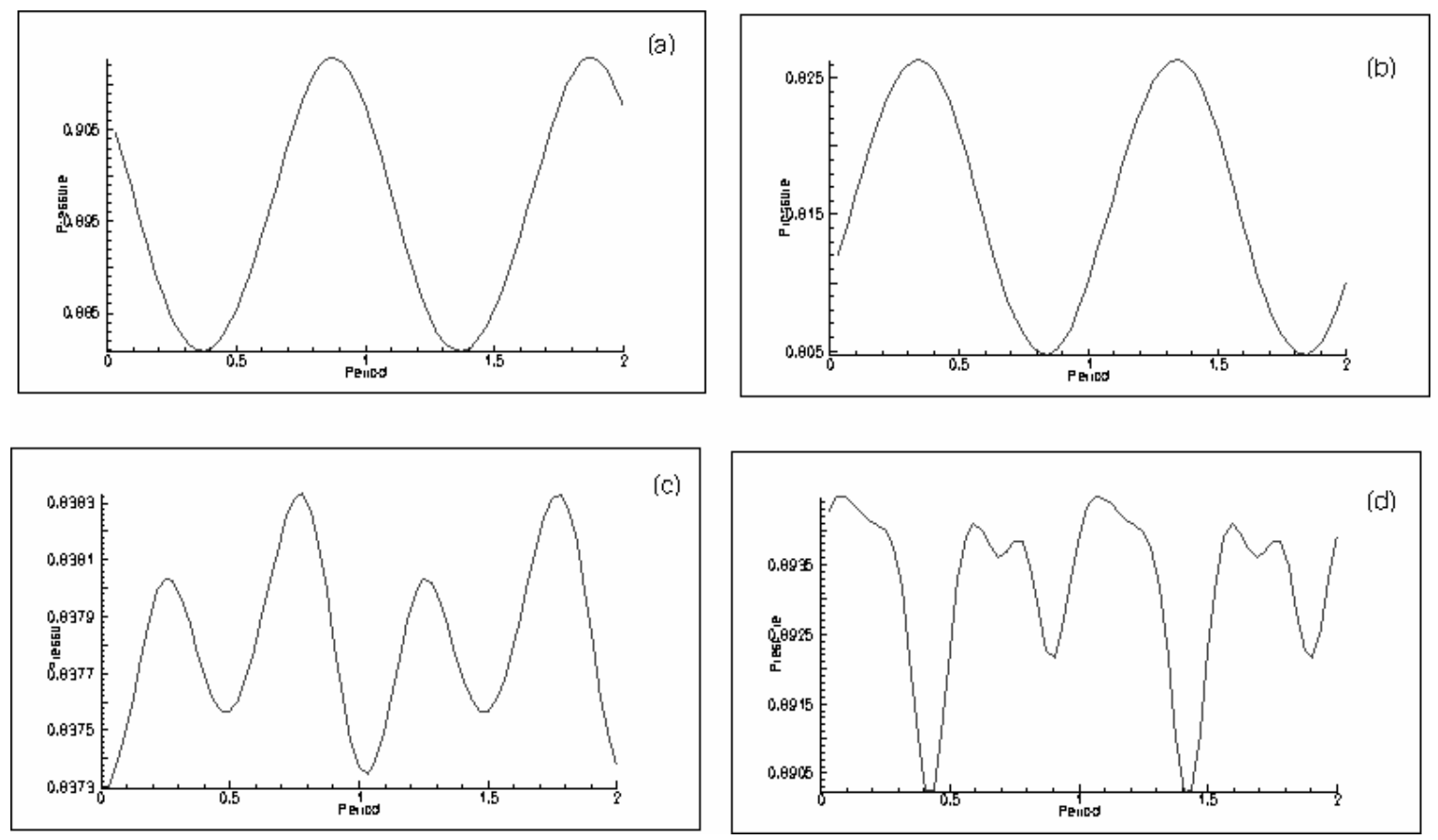

Figure 10.-Converged waveforms for two frequency (BPF+2BPF) excitation, $a_{1}=0.03, a_{2}=0.003$. (a) pressure surface (mid chord). (b) suction surface (mid chord). (c) inflow plane $(-1.5,-0.3)$. (d) outflow plane $(1.5,0.0)$. 

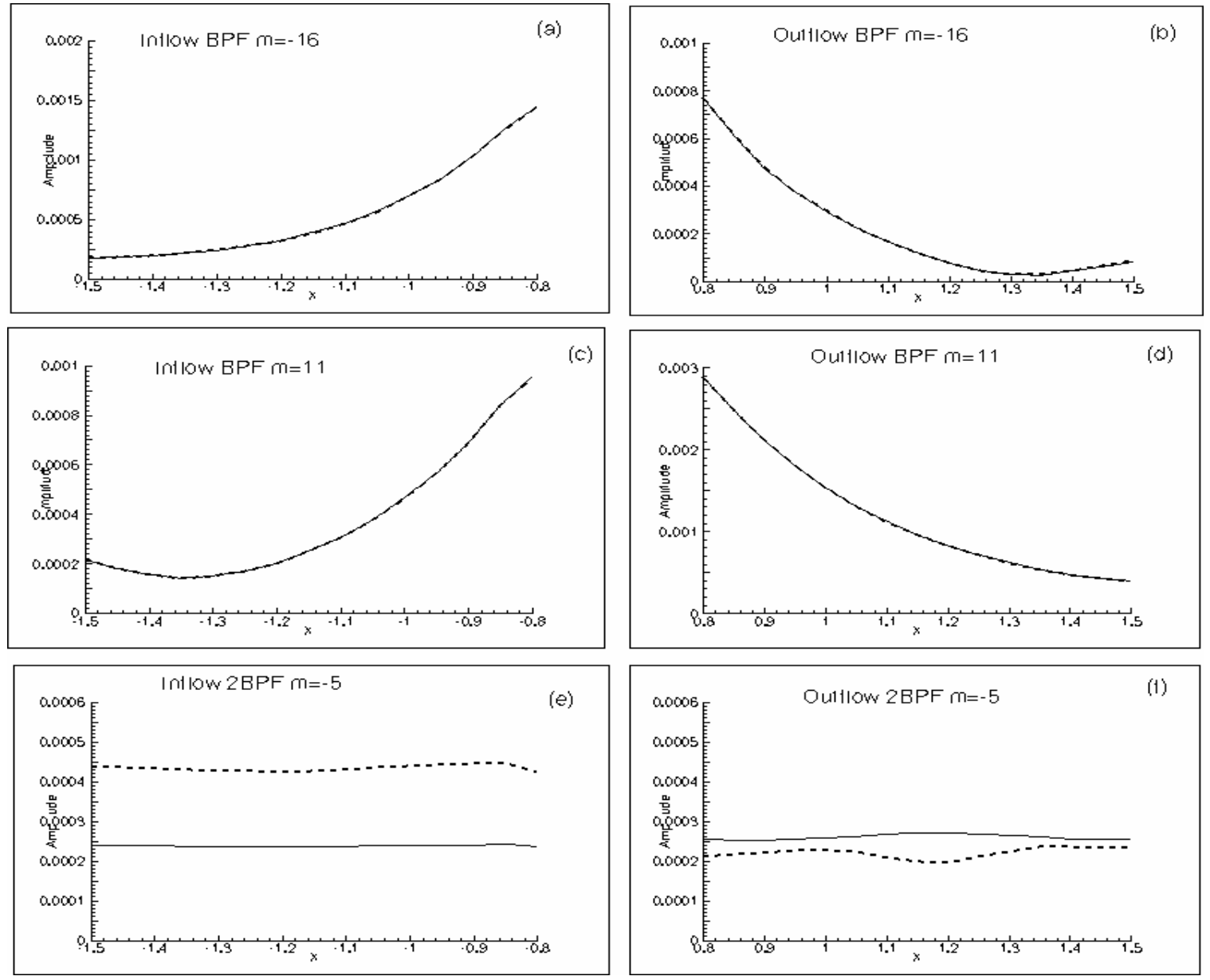

Figure 11.- Single frequency and two frequency excitations: dashed line BPF+2BPF, $\mathrm{a}_{1}=0.03$, $\mathrm{a}_{2}=0.003$. solid line BPF or $2 \mathrm{BPF}, \mathrm{a}_{1}=0.03$ or $\mathrm{a}_{2}=0.003$.
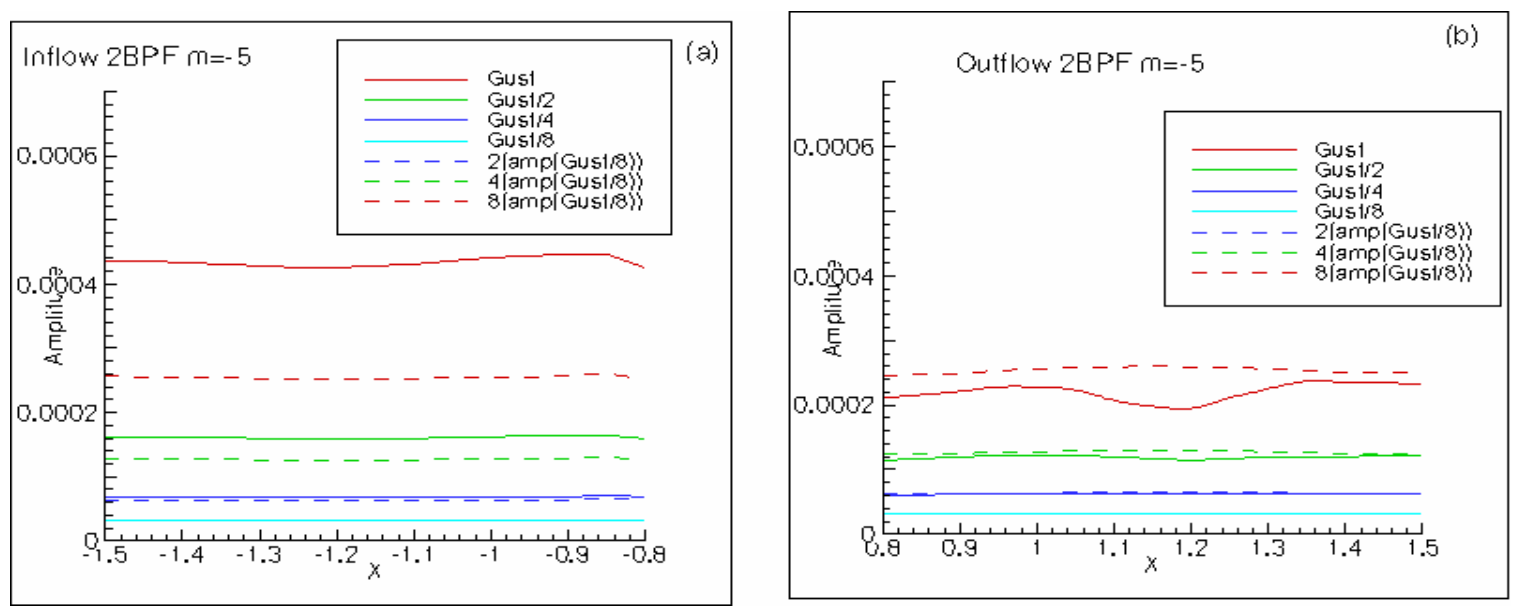

Figure 12.- Response amplitudes for different excitation amplitudes: Gust: $a_{1}=0.03, a_{2}=0.003$; ratios $1 / 2,1 / 4$, and $1 / 8$ applied to both $\mathrm{a}_{1}$ and $\mathrm{a}_{2}$ excitation amplitudes. 

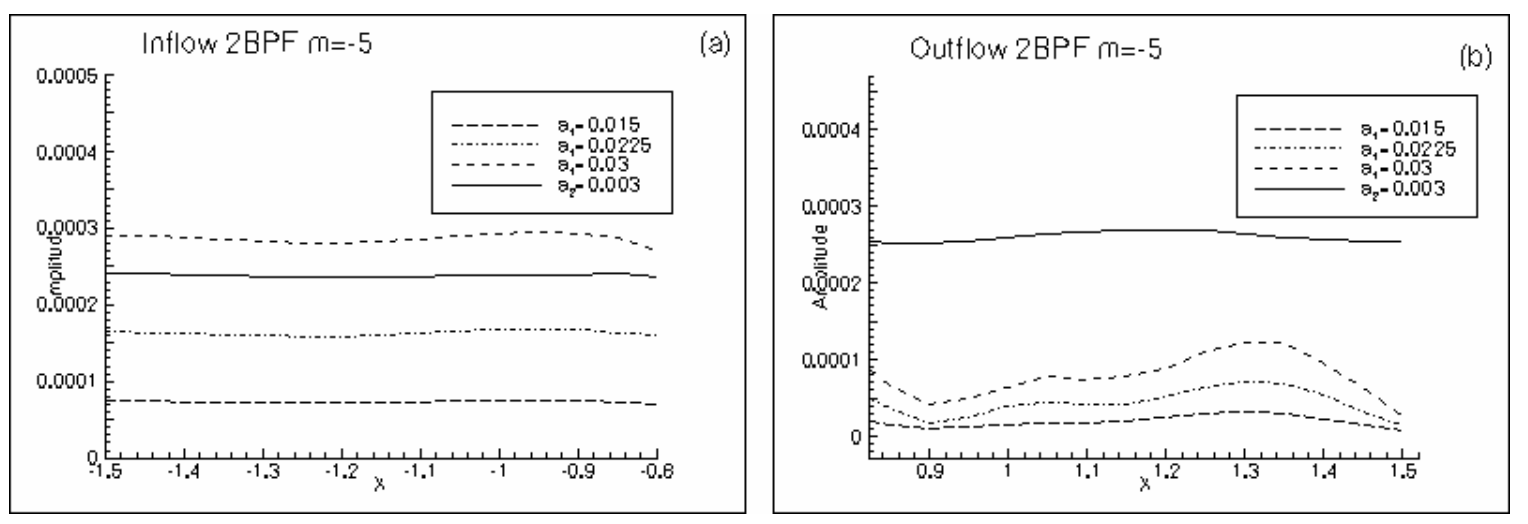

Figure 13.-BPF excitation and $2 \mathrm{BPF}$ generation due to self interaction: compared with the response of $2 \mathrm{BPF}$ alone excitation.
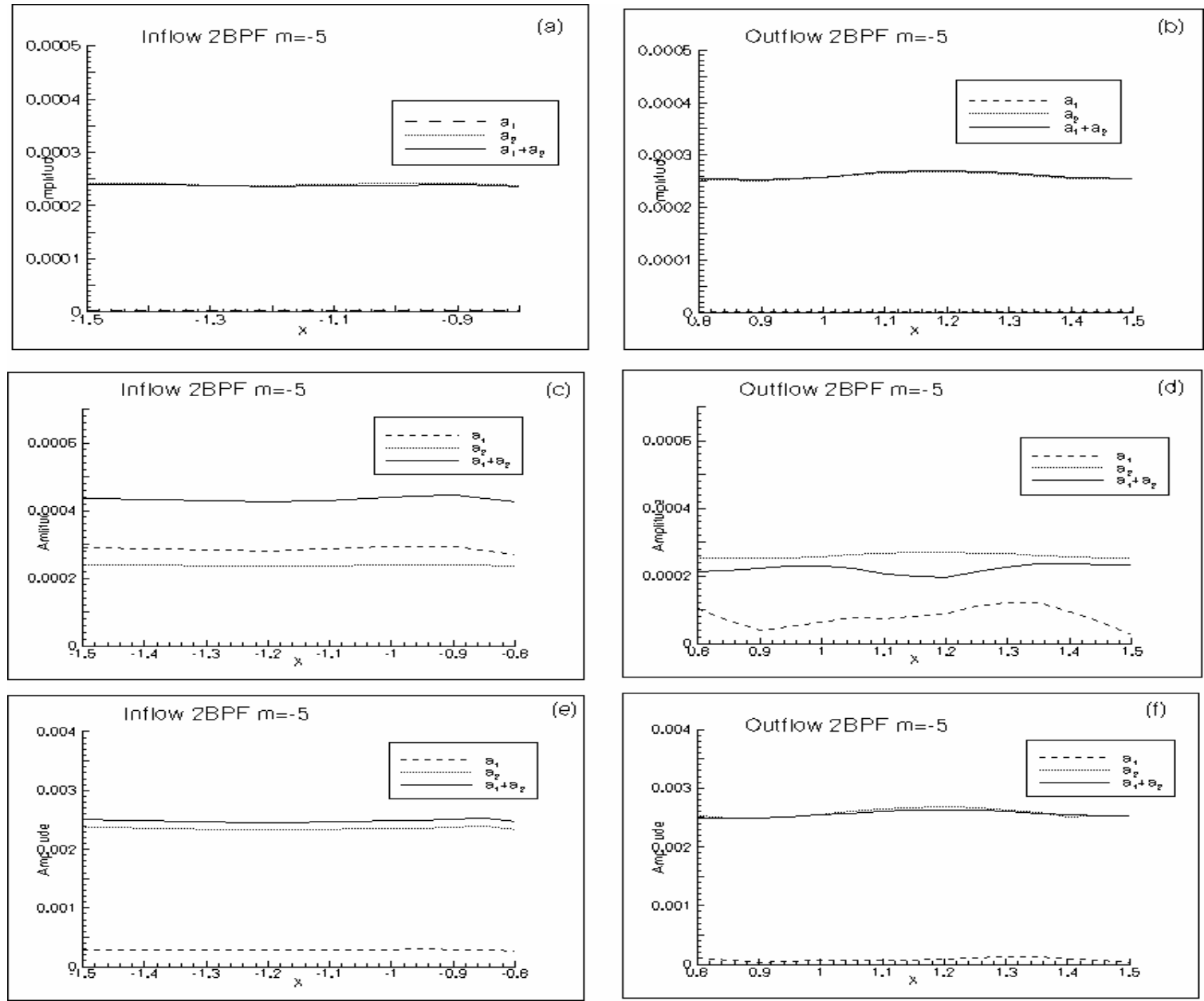

Figure 14. - Two frequency excitations: (a) and (b): $a_{1}=0.003, a_{2}=0.003$. (c) and (d): $a_{1}=0.03$, $\mathrm{a}_{2}=0.003$. (e) and (f): $\mathrm{a}_{1}=0.03, \mathrm{a}_{2}=0.03$. 


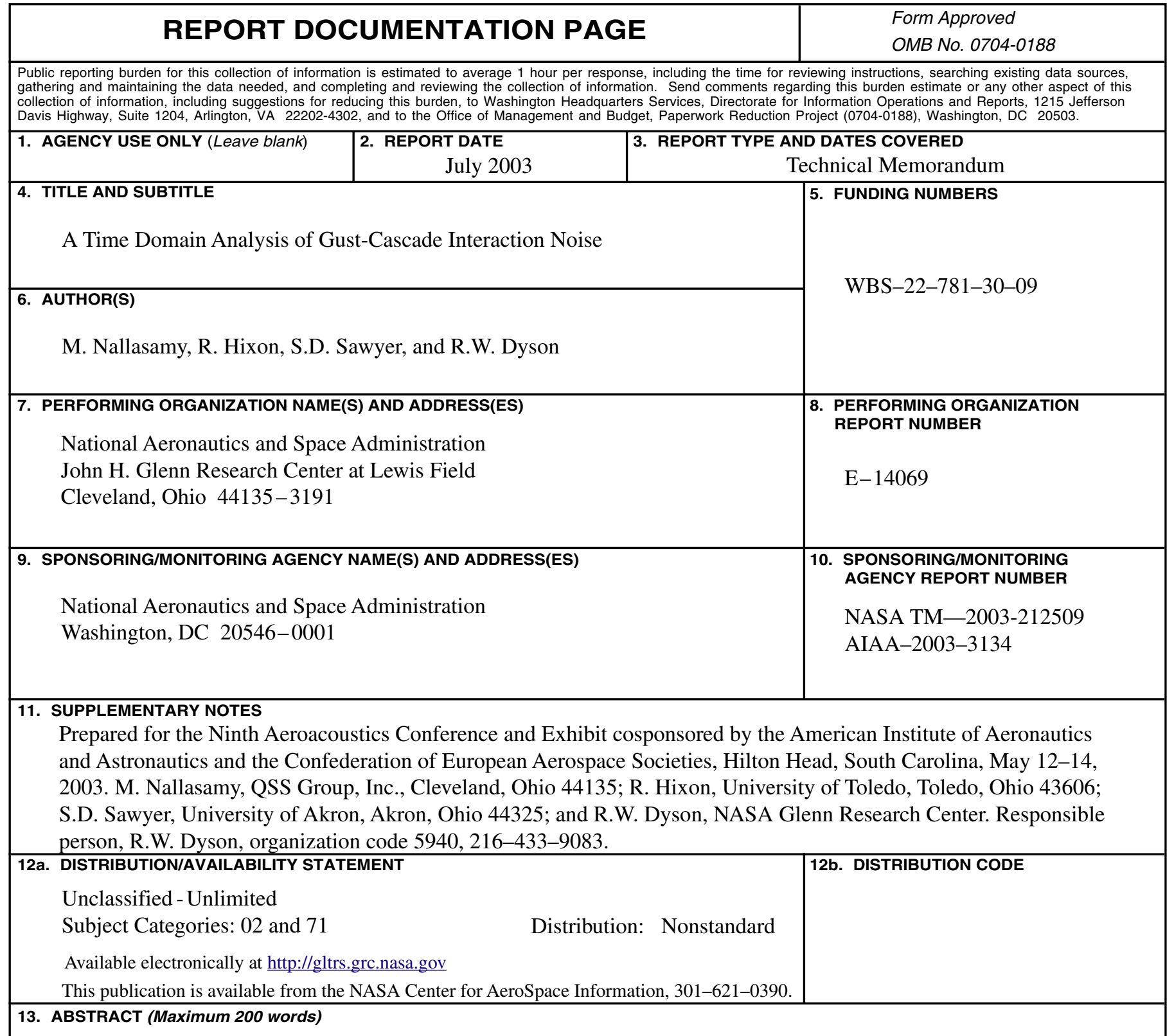

The gust response of a 2-D cascade is studied by solving the full nonlinear Euler equations employing higher order accurate spatial differencing and time stepping techniques. The solutions exhibit the exponential decay of the two circumferential mode orders of the cutoff blade passing frequency (BPF) tone and propagation of one circumferential mode order at $2 \mathrm{BPF}$, as would be expected for the flow configuration considered. Two frequency excitations indicate that the interaction between the frequencies and the self interaction contribute to the amplitude of the propagating mode.

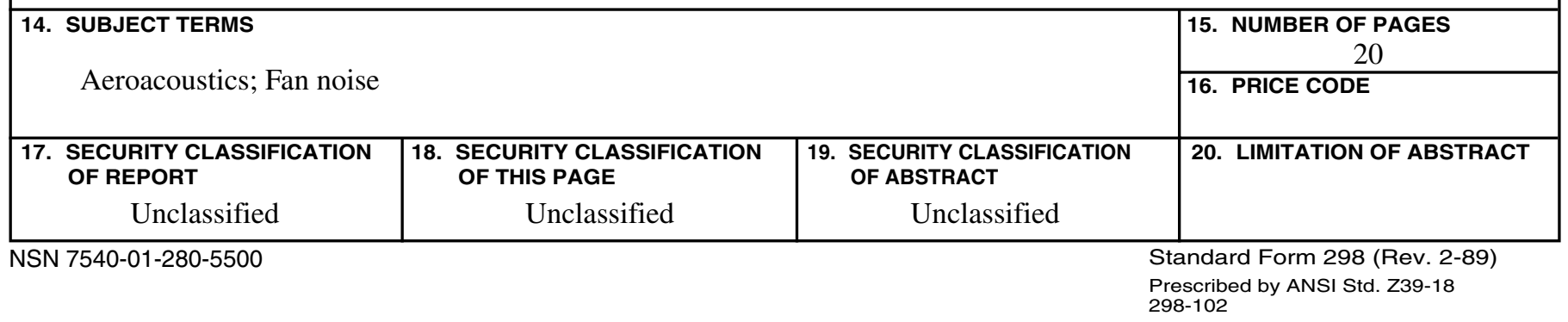

